\title{
REPRESENTAÇÕES DAS TRANSFORMAÇÕES ESPACIAIS: BREVES CONSIDERAÇÕES SOBRE A PAISAGEM URBANA ${ }^{1}$
}

Lidiane Aparecida Alves ${ }^{2}$

\section{Resumo}

A categoria de análise paisagem é essencial à Geografia, na medida em permite tecer considerações sobre o espaço geográfico considerando os processos naturais e sociais, interagindo e manifestando integrada e harmonicamente. Neste sentido, as paisagens são individuais e dinâmicas, pois refletem as características de determinada civilização e meio. Assim, para a compreensão da paisagem, considerar a cultura, evolução temporal sem desconsiderar o meio ambiente é essencial. No âmbito do espaço urbano, os estudos da paisagem viabilizam a compreensão de diversas características de uma cidade, considerando aspectos humanos e físico-naturais. A paisagem urbana resulta da estruturação da sociedade sobre uma paisagem natural, nela estão presentes símbolos, formas, valores, etc. A partir dessa perspectiva o presente artigo busca tecer considerações, apresentando aspectos introdutórios acerca de algumas concepções de paisagem no âmbito dos estudos geográficos, focando fundamentalmente a questão das paisagens urbanas.

Palavras-chave: Paisagem, Urbano, Dinâmica, Sociedade, Natureza.

\begin{abstract}
The analysis category landscape is essential to geography, as to make observations on space considering the natural and social processes, interacting and expressing integrated harmoniously. In this sense, the landscapes are individual and dynamic, they reflect the characteristics of civilization and environment. Thus, to understand the landscape, consider the culture, the time evolution without disregarding the environment is essential. As part of the urban landscape studies enable the understanding of various features of a city, considering the human and physical nature. The urban landscape is clear from the structure of society on a natural landscape, it is these symbols, shapes, values, etc. From this perspective the present article seeks to make

\footnotetext{
${ }^{1}$ A discussão central desse artigo, em parte, partiu-se de um trabalho de conclusão de curso e de uma disciplina cursada no mestrado da Universidade Federal de Uberlândia, intitulada: Tópicos Especiais em Geografia: CULTURA, CULTURAS POPULARES E PATRIMONIO CULTURAL POPULAR, ministrada pelo Prof. Dr. Carlos Rodrigues Brandão.

${ }^{2}$ Mestranda do curso de geografia da Universidade Federal de Uberlândia. E-mail: lidianeaa@ yahoo.com.br
} 
observations, with introductory aspects on some conceptions of landscape in the context of geographic studies, mainly focusing on the issue of urban landscapes.

Keywords: Landscape, Urban, Dynamics, Society, Nature.

\section{Introdução}

A ciência geográfica e a categoria de análise paisagem apresentam-se consubstanciais e complementares, conforme ressaltado por Bertrand e Bertrand (2007, p.270), não há paisagem sem geografia, e tampouco há geografia sem paisagem ${ }^{3}$, apesar da interdisciplinaridade da paisagem, que também é abordada por outras ciências. Segundo Moraes (1991, p. 14) "[...] a paisagem, posta como objeto específico da Geografia, é vista como uma associação de múltiplos fenômenos, assegurando a concepção de ciência de síntese”. De outro modo, conforme afirma Salgueiro (2006, p. 94), na perspectiva dos pensadores da escola francesa, como Monbeig, a geografia era caracterizada como uma ciência explicativa, sendo a paisagem campo de estudos do geógrafo. Ainda segundo Monbeig é inerente a este profissional a capacidade de descrição, onde a paisagem deve ser abordada tanto sob o aspecto sensível, bem como uma representação do espaço geográfico.

A origem da geografia remonta à antiguidade clássica, (MORAES; COSTA 2000, p.464); nesse período o que atualmente é considerada ciência geográfica, era visto como conhecimentos práticos, empíricos e descritivos, utilizados para esquematizar roteiros de viagens e para descrever a terra. No século XVIII, a partir de análises comparativas entre diferentes civilizações possibilitadas pelas viagens de colonização surgiu a geografia humana, (DEMANGEON, 1952 apud NOBRE, 2001, p.6) com sua cientificidade assegurada pelas incursões dos geógrafos naturalistas alemães, Alexander Von Humboldt e Karl Ritter, que, apesar de adotarem vieses diferentes, demonstraram as relações de causa e efeito nas interações dos fenômenos naturais e sociais. O primeiro estudou a influência dos fatores físicos nas formações vegetacionais utilizando o método comparativo, produzindo uma Geografia considerada como ciência de síntese e o segundo enfatizou, que além dos elementos físico-naturais, o homem promove transformações, que são objeto de estudo dentro da natureza.

Além disso, há que se destacar as contribuições do também geógrafo alemão Friedrich Ratzel, que em seu trabalho denominado antropogeografia, viabilizou o entendimento das primeiras concepções de paisagem ao considerar a relação homem meio e a presença de

\footnotetext{
${ }^{3}$ Além da paisagem, destacam-se como conceitos chave da Geografia: território, região, espaço e lugar, cujos conceitos se apresentam correlacionados, e simultaneamente guardando suas particularidades.
} 
diferentes valores entre os agrupamentos humanos, bem como do geógrafo francês Paul Vidal de La Blache, que refutou o determinismo, sustentando a idéia de que o homem poderia moldar o meio ambiente, contribuindo assim para a compreensão da paisagem enquanto construção humana.

O termo paisagem pode receber diferentes acepções segundo a língua em que é empregado. Assim, landschaft surgiu por volta do século XVI na Alemanha, de acordo com Holzer (1999, p. 152) referindo a uma associação entre sítio e os seus habitantes, ou seja, uma associação morfológica e cultural, foi transmutado para o inglês Landscape por Sauer que, enfatizava a manutenção do sentido original. Todavia, com sentido diferente do vocábulo francês paysage associada ao renascimento e, às representações artísticas, como pinturas, demonstrando a perfeição.

Durante o século XVII, no contexto do surgimento do Estado-Nação, a noção de paisagem pautou-se fundamentalmente, na representação da realidade, no visível. Contudo, mais tarde ao considerar a relação homem natureza, passou-se a considerar implícitos na paisagem a dialética entre o natural e o social, reconhecendo paisagens enquanto produto do trabalho humano sobre o meio físico.

Entre o século XIX e início do século XX, mesmo permeada por incertezas e confusões, e, ainda sem grande rigor científico, a paisagem passou a ocupar lugar de destaque nas teses e discussões. Até o fim do século XIX, segundo Santos (1997, p.63) era comum a associação de paisagem e região, o que atualmente é inconcebível, posto as facilidades de trocas viabilizadas pelo processo de globalização.

Em meados do século XX, entre as décadas de 1920 e 1950, o termo paisagem foi julgado ao esquecimento, mantendo-se afastado das discussões acadêmicas, pelo seu caráter fugaz e aventureiro, como destacado por Bertrand e Bertrand (2007, p.230). Contudo, na década de 1960 os questionamentos e o movimento de renovação das pesquisas científicas viabilizaram o desenvolvimento de vários campos teóricos, ampliando as possibilidades de análise de determinado objeto. Esses avanços refletiram na retomada dos estudos sobre paisagem, visto a sua potencialidade para os debates que envolvem questões ambientais e sociais; econômicas, culturais, políticas. Dentre os trabalhos que se destacam no século XX está o de Otto Schlüter, que definiu paisagem cultural justificando a importância dos aspectos culturais de determinado grupo social na configuração da paisagem.

Com a retomada dos estudos sobre a paisagem foram significativos os ganhos, porém, em decorrência da complexidade inerente à mesma, ela pode ser apreendida de diversas maneiras segundo diferentes perspectivas, existe uma grande dificuldade em defini-la, visto 
que são vários os conceitos de paisagem, apresentando, ainda, aspectos incógnitos. No entanto, apesar das dificuldades em lidar com essa categoria de análise, destaca-se o crescimento do número de monografias que a abordam.

A paisagem nos permite tecer análises sobre o espaço geográfico, considerando os processos naturais e sociais, interagindo e manifestando integrada e harmonicamente. $\mathrm{Na}$ paisagem os aspectos sociais e naturais são híbridos, a cultura, economia e política estão intrinsecamente relacionadas com o meio ambiente, não de forma relativista (o meio apenas como uma construção social), tampouco, reducionista (com o meio determinando o social), mas numa relação em equilíbrio.

Neste sentido, a paisagem assume uma interdisciplinaridade, entre as ciências humanas e naturais, a qual pode ocasionar certo incômodo epistemológico, mas que em contrapartida também permite o diálogo entre os estudos etnográficos e ecológicos, conforme afirma Silveira (2008, p.39) ruindo barreiras entre os campos social e natural. Ao abarcar a relação de determinada sociedade com o meio ambiente, a paisagem constitui espaço simultaneamente social e ecológico, com marcas e identidades próprias, sendo um conceito útil em análises que perpassam por diferentes dimensões do conhecimento. No contexto atual, devido às mudanças de valores e concepções, a compreensão da paisagem passa a desempenhar um papel ainda maior que outrora, fundamentalmente, nos estudos etnográficos.

No âmbito dos estudos de geografia urbana, a paisagem assume um papel fundamental, afinal a cidade e o urbano consistem em objetos de estudo complexos, e necessitam para a sua compreensão de um ponto de vista holístico que permita a apreensão do geral sem negligenciar o particular, pois, enquanto condição, meio e produto das ações realizadas pela sociedade, a cidade reúne, ao mesmo tempo, uma grande variedade de elementos.

A cidade e seus espaços internos apresentam-se em constante movimento revelando permanências, transformações, deteriorações, revitalizações e refuncionalizações de acordo com os valores adotados pela sociedade impostos pelo novo modo de produção capitalista. As atividades urbanas possuem grande capacidade de adaptação de acordo com a demanda, com isso cada momento é marcado por diferentes padrões de produção e consumo, assim como de relações sociais que, por conseguinte, refletem em diferenciações socioespaciais, as quais constituem diferentes paisagens. Nesse contexto, a paisagem viabiliza a apreensão da manifestação formal do urbano, considerando além da aparência, a compreensão do urbano enquanto processo. 
A partir dessa perspectiva o presente artigo procura tecer considerações, apresentando aspectos introdutórios, acerca de algumas concepções de paisagem no âmbito dos estudos geográficos, focando fundamentalmente a questão das paisagens urbanas. Espera-se a partir das discussões apresentadas colaborar como as reflexões sobre essa categoria de análise geográfica, bem como sobre sua importância no âmbito dos estudos urbanos. Para tanto, foram consideradas algumas das contribuições mais relevantes no que concerne a temática abordada.

\section{Alguns apontamentos sobre as concepções de paisagem nos estudos geográficos}

A paisagem constitui um dos conceitos clássicos da investigação geográfica, assumindo ao longo dos anos acepções e posições variadas no âmbito do pensamento geográfico. Ocupou posto de destaque na disciplina geográfica na Alemanha, na França e nos Estados Unidos, na ocasião dos estudos dos geógrafos naturalistas, como Humboldt, quando era associada "a porções do espaço relativamente amplas que se destacavam visualmente por possuírem características físicas e culturais suficientemente homogêneas para assumirem uma individualidade" (Holzer, 1999, p.151). Em outros períodos, fundamentalmente, quando a geografia clássica incorporou bases epistemológicas relacionadas ao positivismo lógico, segundo Corrêa e Rosendahl, (1998, p.7) a paisagem teve sua importância relegada a uma posição secundária, suplantada pela ênfase nas categorias de análise região, espaço, território e lugar, considerados mais adequados às necessidades contemporâneas. Porém, a partir da emergência de uma Nova Geografia Cultural, o conceito foi retomado e ganhou novos conteúdos, devido à incorporação de noções como percepção, representação, imaginário e simbolismo inerentes a essa disciplina, conforme destaca Castro (2002).

No decorrer dos anos o conceito de paisagem assumiu uma polissemia e amplitude conceitual devido às diversas dimensões, como a morfológica, funcional, histórica, espacial e simbólica nela imbricadas e de acordo com as diferentes concepções teórico-filosóficas adotadas pelos autores.

Dentre as definições que lhe foram atribuídas, destaca-se como uma das mais holísticas, a proposta por Carl Troll (1996), segundo a qual, a paisagem geográfica era comparada a um "ecossistema", onde os seres humanos, organizados em diferentes grupos, constroem seus espaços, com os aspectos visíveis e não visíveis articulados entre si. Neste sentido, a paisagem seria o resultado da dinâmica e interação dos aspetos naturais e humanos, apresentando-se impregnada de significados, simbologias e valores. Carl Troll abriu caminho para a distinção entre paisagem natural e cultural, ao considerar elementos relacionados às 
dimensões fenomenológicas inerentes à sua complexidade, que, inicialmente foram relegados, posto que a paisagem era compreendida a partir da realidade objetiva, ou seja, do que era passível de ser visto e catalogado.

Nas abordagens que consideram a coexistência de formas naturais e culturais manifestas na paisagem, insere-se a perspectiva de Bertrand e Bertrand (2007, p.232), segundo a qual a paisagem é uma produção interna, nascida da sociedade, mediando sociedade e natureza, ou seja, um produto social materializado de acordo com as características culturais, políticas e econômicas vigentes em determinada sociedade e época.

A paisagem é o reflexo e a marca impressa da sociedade dos homens na natureza. Ela faz parte de nós mesmos. Como um espelho, ela nos reflete. É ao mesmo tempo ferramenta e cenário. Como nós e conosco, ela evolui, móvel e frágil. Nem estática, nem condenada. [...]. (BERTRAND e BERTRAND 2007, p.263).

De maneira semelhante, Schier (2003, p. 82), aponta que em grande parte dos estudos, no período entre os séculos XIX e XX, sobretudo após a década de 1970, as paisagens eram consideradas como:

[...] entidades espaciais dependentes da história econômica, cultural e ideológica de cada grupo regional e de cada sociedade e, se compreendidas como portadoras de funções sociais, não são produtos, mas processos de conferir ao espaço significados ideológicos ou finalidades sociais com base nos padrões econômicos, políticos e culturais vigentes. (SCHIER, 2003, p. 82).

Nesta concepção culturalista, a paisagem é simultaneamente marca e matriz, isto é, marca na medida em que apresenta elementos humanos passíveis de serem percebidos, e matriz ao apresentar sentidos para os elementos perceptíveis; isto porque a paisagem " $[. .$. expressa uma civilização e participa dos esquemas de percepção e concepção e de ação, ou seja, da cultura” (BERQUE, 2000, p.86). Esse autor destaca a relação dialética entre a sociedade e a paisagem em sua produção, reprodução e apreensão, ressaltando a necessidade de considerar tanto a sociedade como sujeito observador, quanto como agente, de modo integrado à paisagem.

Neste sentido, as dinâmicas da natureza e da sociedade, de maneira combinada, produzem no espaço diferentes paisagens, que constantemente passam por transformações. E que, diferentemente do que foi proposto pela geografia regional, são individuais segundo as características de seu sítio e história, embora possam apresentar elementos com certa similaridade em outras regiões. Assim, para a compreensão da paisagem, considerar a cultura e a evolução temporal é essencial, pois a paisagem é vista como o espelho de uma civilização. 
Considerando as transformações da paisagem, Santos (1978) apud Bertrand e Bertrand (2007, p.225), coloca que, "nada na paisagem muda ao mesmo tempo, na mesma velocidade ou na mesma direção", é comum a concretização de situações de inércias e histerese nas paisagens, que são segundo Santos (1996, p.66) “como um palimpsesto, isto é, o resultado de uma acumulação, na qual algumas construções permanecem intactas ou modificadas, enquanto outras desaparecem para ceder lugar a novas edificações”, ou ainda, ocorrem mudanças nos usos, posto que, conforme destaca Santos (1997, p.73), "a sociedade - sempre em movimento - se adéqua à paisagem”. Ademais, as paisagens apresentam ritmos de transformações diferenciados, sendo mais lentos, até mesmo seculares, nas paisagens naturais e mais rápidos, por exemplo, nas paisagens citadinas, conforme observado por Troll (1996).

A paisagem abarca o encontro do sensível e do subjetivo, das memórias e culturas, com o campo material, um meio ambiente, cujos elementos, físicos e sociais, estão sujeitos a percepção dos indivíduos, a qual conduzirá à compreensão de cada paisagem de acordo com a capacidade individual.

Visto essas considerações deve-se ponderar no processo de percepção da paisagem, sem desconsiderar o funcionamento do meio ambiente e da sociedade, as dimensões sensível e simbólica, afinal, as marcas de uma sociedade, de seu processo de reprodução em determinado território, estão na paisagem. Nas palavras de Bertrand e Bertrand (2007, p.251) ela é um "suplemento da cultura," um fator identitário, na medida em que exprime os aspectos materiais, bem como imateriais consolidados ao longo da história da humanidade.

Diante dessas particularidades, a fim de se compreender a essência do fenômeno da paisagem, verifica-se a necessidade de considerar os elementos científicos e apreensões sensíveis, bem como os elementos humanos e não humanos, pois segundo Gomes (1997, p.31) muitas concepções de paisagem decorrem de experiências pessoais, onde são somados aspectos cotidianos.

O que o geógrafo entende por paisagem é o resultado, ou o resumo de tudo o que reconheceu ou conheceu através do método indutivo [...] Isso tudo visto e analisado segundo a perspectiva de seu ponto de vista e conhecimento acumulado. Assim, a paisagem é, sobretudo uma representação. (GOMES, 1997, p.31).

Além disso, a paisagem deve ser apreendida como um conjunto, uma totalidade, e não com seus elementos considerados de maneira isolada (TROLL, 1996, p.7). É necessário acumular e desvendar os "obstáculos conceituais e metodológicos e o que parece ser um tecido de contradições". Para tanto, o ponto de partida é "enumerar as principais "qualidades" 
que se reconhecem habitualmente à paisagem", as quais de modo geral vêm de categorias inerentes a outros campos do conhecimento, conforme alerta Bertrand e Bertrand (2007, p.220-221). Esses autores enumeram alguns postulados intrínsecos à apreensão da paisagem, como:

a) A paisagem se impõe na sua trivial globalidade: é preciso partir do banal e do global desembaraçando-se (na medida do possível) de todo pressuposto disciplinar, metodológico e finalista.

b) A paisagem é um objeto socializado, uma imagem, que só existe através do fenômeno fisiológico da percepção e de uma interpretação sociopsicológica. [...]

c) A paisagem nem por isso deixa de ser uma estrutura natural, concreta e objetiva, Isto é, independente do observador [...]

d) A imagem social da paisagem é produto de uma prática econômica e cultural [...]

e) A especificidade da paisagem decorre menos de ser mais "complexa" e mais "heterogênea" do que os objetos científicos habituais do que da dificuldade de dominar as grandes categorias metafísicas: o natural e o cultural, o espaço e o social, o "objetivo" e o "subjetivo". (BERTRAND e BERTRAND (2007, p.221).

No âmbito da Geografia cultural foi instituída, na década de 1920 por Carl O. Sauer, a

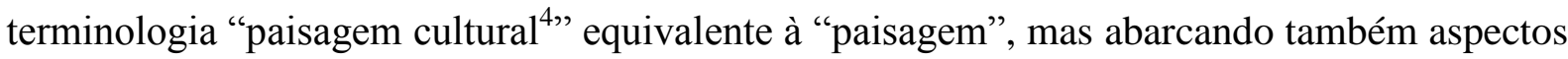
culturais. A paisagem para Sauer $(2004$, p.14) seria:

[...] o equivalente em inglês para o termo que os geógrafos alemães estão usando amplamente, e tem estritamente o mesmo significado: uma forma da Terra na qual o processo de modelagem não é de modo algum imaginado como simplesmente físico. Ela pode ser, portanto, definida com uma área composta por uma associação distinta de formas, ao mesmo tempo físicas e culturais.

Ainda de acordo com esse autor a paisagem cultural é formada a partir da paisagem natural por um grupo cultural, podendo ser transformada pela introdução de novos elementos culturais, bem como, pelas diferentes condutas do homem. Assim, é constituinte da paisagem cultural, um agente representado pela cultura e um meio representado pela paisagem natural, que através do tempo são transformados a partir da concretização de formas, que podem ser da habitação, da produção e uso da terra, para comunicação, deslocamento, enfim, meios para a reprodução, cujos elementos, refletem um determinado modo de vida, interagindo com um quadro natural.

A partir da perspectiva da nova Geografia Cultural, a paisagem é concebida como um texto passível de ser lido e interpretado, considerando sua origem, morfologia e estrutura de maneira associada com outros aspectos, como os gêneros de vida e as manifestações culturais, de modo a permitir que as análises e sua apreensão ultrapassem a dimensão material. Neste

\footnotetext{
${ }^{4}$ Cujo tema juntamente com: cultura, área cultural, história da cultura e ecologia cultural constituem o cerne dos estudos da geografia cultural.
} 
sentido, Santos (1997) reitera a importância de se ir além da observação, e considerar os aspectos históricos e temporais presentes na paisagem, pois, em seu "funcionamento" coexistem elementos de diferentes períodos desempenham funções de acordo com as necessidades do momento presente. Em seus estudos sobre a paisagem urbana Carlos (1994) concorda com a concepção de Santos, para a autora "a paisagem de hoje guarda momentos diversos do processo de produção espacial [...]". Além disso, permeiam na paisagem uma grande quantidade e complexidade de elementos simbólicos, os quais, conforme Peixoto (2004, p.17), muitas vezes são invisíveis.

No processo de compreensão da paisagem a partir das dimensões subjetivas e objetivas, esta é analisada segundo visões multidirecionais, pois cada indivíduo possui uma maneira singular de observar determinado objeto e considera como relevantes diferentes elementos. Nesse sentido, Bertrand e Bertrand (2007, p.114) citam como exemplo o solo, que corresponde desde o perfil pedológico até um perfil social com a sua representação cultural, a fertilidade. Deste modo, a paisagem representa valores e simbologias, que abarca além do que é passível de ser visualizado por um agente externo, mas também o que é vivido por determinado grupo sociocultural.

Além disso, de outro modo,

[...] as paisagens são contextos visuais da existência quotidiana, [...] são simultaneamente óbvias e esquivas; aparentemente, sabemos exatamente o que são, até ao momento em que temos que pensar e escrever sobre elas, ou modificá-las de alguma maneira; e então tornam-se enigmáticas e frágeis (Relph, 1987, p. 12-13).

\section{Paisagens Urbanas: representações da reprodução social}

Embora as primeiras cidades tenham surgido há cerca de 5000, o processo de urbanização se intensificou somente no século XX. As distintas questões referentes ao fenômeno urbano passaram a constituir objeto de estudo de diversas ciências, sob as mais variadas correntes filosóficas. Apesar da potencialidade da geografia, ao considerar a dinâmica socioespacial, a cidade constitui um tema relativamente recente nos debates da ciência geográfica. Segundo Abreu (2006, p.129) os estudos dos núcleos urbanos foram integrados ao campo de investigação geográfica somente no início do século XX - na segunda década desse século -, inicialmente pautados em um viés naturalista, decorrente de influências da escola francesa.

Com a intensificação do processo de urbanização, as cidades assumiram posto de destaque na organização do espaço geográfico, visto que as mesmas polarizam uma gama de 
funções, políticas, econômicas e culturais; são constantemente modificadas pelas ações da sociedade, abarcando conteúdos variados e, portanto sendo necessária expressiva atenção dispensada à questão urbana. Considerando a cidade como produto e condicionante social, destaca-se a importância dos aspectos econômico, político e cultural, para a compreensão da urbanização, da cidade, e, por conseguinte para o entendimento das singularidades, resultantes das tradições e valores de determinada sociedade que age produzindo paisagens incríveis. Os estudos da paisagem urbana viabilizam a compreensão de diversas características de uma cidade, considerando aspectos humanos e físico-naturais.

A partir da concepção de que nos estudos referentes aos aspectos da realidade, dos espaços naturais e socialmente construídos, a exemplo o urbano e a cidade, podem ser lidos como um texto tem-se que estes são impregnados por inúmeras figuras de linguagem, como metáforas, metomínias e sinédoque (CORRÊA, 2006, p. 143), torna-se possível a construção de significados e a compreensão de vários aspectos da organização do espaço urbano representados na paisagem. O processo de verticalização, por exemplo, pode ser analisado a partir da dimensão simbólica, envolvendo as noções modernidade e status social.

No espaço urbano a paisagem apresenta formas com valores econômico, político e cultural, nas palavras de Corrêa (1995, p.8) representa a expressão espacial dos processos sociais, sendo, portanto a manifestação formal da reprodução do espaço urbano. Sobre isso, Carlos coloca que o:

[...] intenso e incansável processo de produção e reprodução humanos se materializa concretamente no espaço geográfico, e é apreendido na paisagem através de uma serie de elementos: construções, vias de comunicação, cheios e vazios, etc. Portanto, percebidos e apreendidos em sua manifestação formal: a paisagem (CARLOS, 2005, P.39)

É intrínseca à paisagem urbana a ocorrência de uma gama de transformações em curtos espaços temporais. Sobre isso, Relph destaca que as paisagens são constituídas por uma base material, as construções, e pelas idéias, e, por conseguinte:

\footnotetext{
As paisagens urbanas modernas podem parecer tão estáveis e duradouras como as suas antecessoras, mas na realidade estão constantemente ameaçadas pela iminência de aniquilação completa. Apesar de toda a sua enormidade e solidez, de toda a sua sofisticação electrónica e dos cenários imaginhados, as cidades modernas são as mais frágeis de toda a história. (RELPH, 1987, p.122).
}

Além disso, o autor destaca que no processo de transformação da paisagem urbana encontram-se articulados elementos sociais, econômicos, de planejamento, entre outros. 
Sendo que no decorrer dos anos as paisagens urbanas se desenvolvem seguindo diferentes pressupostos.

A cidade é concebida como uma reconstrução da realidade, elaborada e reelaborada por indivíduos e grupos sociais a partir de práticas e experiências, (MOSCOVICI apud CORRÊA, 2006, p. 155). Nesse processo os elementos naturais são modificados, a partir da construção de novos equipamentos necessários à reprodução social, de modo que para a compreensão das transformações da paisagem urbana é necessário que seja considerada a interação sociedade e natureza. Analisando as transformações da paisagem urbana, Carlos (1994, p.44) coloca que a "a paisagem urbana é a expressão da ordem e do caos, manifestação formal do processo de produção do espaço urbano, colocando-se no nível do aparente e do imediato".

A paisagem urbana pode ser definida como o conjunto de espaços onde se desenvolve o cotidiano da vida de seus habitantes. Ela é resultante da interação do sítio, da sociedade e do espaço construído, sendo: o sítio, o meio físico, a paisagem natural, envolvendo seus componentes bióticos; a sociedade, os vários grupos sociais que disputam espaços na cidade e o espaço construído, a paisagem humanizada, representado pelos edifícios, vias, áreas livres, etc (LEMENHE, 1997, p.163). Essas duas paisagens, a natural e a humanizada, constituem objeto de estudo de historiadores, sociólogos, antropólogos, arquitetos e geógrafos, posto que a sua apreensão envolve aspectos de ordem ambiental e social. Além disso, a sobreposição delas é que constitui a paisagem urbana.

No decorrer do processo de reprodução social, incessantemente paisagens são produzidas e transformadas. Sendo assim, conforme destacado por Carlos (2005, p. 40) "o primeiro aspecto que chama a atenção quando se observa a paisagem urbana é o choque dos contrastes e das diferenças". Como exemplos das diferentes paisagens produzidas no espaço urbano, têm-se a construção de novos loteamentos, seja de residências populares ou de condomínios fechados, a implantação de novas infraestruturas de comunicação, energia, tecnológicas, viárias, a implantação de empreendimentos industriais, além do caso dos centros das cidades que de acordo com Santos (1996, p.66) apresentam "situações sociodemográficas herdadas do passado, evoluções econômicas contraditórias e realizações arquiteturais programadas no contexto de uma revalorização mistificadora do domínio urbano".

As paisagens são únicas e materialmente constituídas, sendo suas formas e objetos determinados por condições técnicas específicas, podendo coexistir diferentes elementos de vários tempos históricos, passados e pelo presente, conforme afirma Santos (1996, p.68-69). Na mesma perspectiva para Carlos (1994, p.46) “a paisagem não é só produto da história, ela 
reproduz a história, a concepção que o homem tem e teve [...] do viver". Outro autor com perspectiva semelhante é Lefebvre, citado por Carlos. Esse autor, ao estudar uma rua parisiense, chegou à conclusão de que coexistem na paisagem edificações de diferentes momentos históricos, passados e presente, reproduzindo uma paisagem singular, marcada por vários períodos históricos.

No contexto das cidades brasileiras, marcadas por um vertiginoso processo de urbanização nas últimas décadas, combinado instauração de um capitalismo depende, acarretou a efemeridade de muitas formas arquitetônicas, seja do casario do sistema colonial ou mesmo das construções representantes do modernismo brasileiro. Nesse contexto, muitas das intervenções na paisagem urbana apagaram memórias e fez desaparecer patrimônios culturais. Sobre a noção de patrimônio cultural Lemenhe (1997, p.169) destaca que envolve, dentre muitas outras, a questão da memória, que não significa apenas passado, mas indica uma relação entre passado e presente, ou seja, significa mudança.

A paisagem urbana reflete a dinamicidade da reprodução social e do capital, que em decorrência das diferenças socioeconômicas, evidencia também a segregação espacial, afinal,

\footnotetext{
Esse intenso e incansável processo de produção e reprodução humana se materializa concretamente no espaço geográfico e é apreendido na paisagem através de uma serie de elementos: construções, vias de comunicação, plantação, etc. Portanto, percebido e apreendido em sua manifestação formal: a paisagem é a vida cotidiana que é percebida através dela (CARLOS, 1994, p.49).
}

As mudanças de valores causadas pelo novo processo produtivo na sociedade globalizada, ao impulsionar significativas transformações na estruturação do espaço urbano conduz a uma maior complexidade na paisagem urbana. Neste contexto, os espaços são (re)estruturados para a acomodação de novas atividades, como exemplo Prigge (2002, p. 52) cita a ocupação de espaços no entorno do núcleo central, antes sem utilização definida, que passam a acomodar diversos tipos da cultura jovem; a tomada dos centros das cidades pelas atividades turísticas, ocasionando a apropriação de locais que outrora eram públicos como as praças, estações ferroviárias, ruas; as ações da iniciativa privada que criam cada vez mais espaços "semipúblicos", como os shopping-centers, ou mesmo privados, como os condomínios fechados - horizontais e verticais; entre outras ações, que levam a constituição de uma cidade cada vez mais fragmentada, com a formação de aglomerados dos "iguais" - ou seja, é cada vez mais comum que os grupos sociais homogêneos se aglomerem.

As instalações de novos usos acarretam, não somente, mudanças e renovações paisagísticas, mas também conduz a os novos "olhares" sobre a cidade, pois segundo 
Montessoro (1999, p.144) “a percepção urbana manifesta-se diante da imagem expressa pelos elementos que constituem o lugar". Neste sentido, apesar de aparentemente imóvel, a paisagem revela-se cambiante implicando mudanças de sentidos dos lugares.

A paisagem urbana resulta da estruturação social, nela estão presentes o espaço construído e também símbolos, valores de determinada sociedade, que constituem a identidade do lugar e são informados e transmitidos pela paisagem (MOURA, 2003. p.11), posto que, conforme destacado por Flusser apud Freitg-Rouanet (2002, p.33), é impossível conceber uma cidade sem criatividade e autenticidade cultural em todos os campos, o literário, o arquitetônico, o estético (artes plásticas, pintura, música, etc). Além disso, segundo Relph (1987) as paisagens modernas abarcam uma gama de aspectos, como as estruturas e espaços facilmente visíveis, e aquelas menos perceptíveis como os túneis dos transportes subterrâneos, não sendo possível considerar todos esses aspectos.

A partir dessas considerações, destaca-se o papel da paisagem na constituição da memória social das cidades, e a importância de preservá-la visto que apresenta características próprias, sendo, portanto segundo Relph (1987, p. 15) as próprias paisagens suas melhores fontes de informação, sobre o que somos, visto que as moldamos e somos moldados por elas.

\section{Considerações Finais}

O termo paisagem apresenta uma gama de sentidos, que apesar das dificuldades em lidar com essa pluralidade de conceitos, esse constitui o diferencial e o valor da categoria de analise paisagem, a qual ocupa posto de destaque no âmbito dos estudos geográficos. Essas dificuldades em definir, identificar, reconhecer e limitar os aspectos da paisagem, no âmbito da Geografia Humanística, explicam-se porque a mesma, segundo Dardel (1990, p. 54) “[...] representa a inserção do homem no mundo, a manifestação do seu ser para com os outros, base de seu ser social".

A capacidade de abarcar diversas dimensões, devido à presença de elementos naturais e antrópicos de maneira interrelacionada, faz da categoria paisagem, simultaneamente complexa e com grande potencialidade para romper, fundamentalmente, na ciência geográfica, com a dicotomia entre a Geografia Física e Geografia Humana, inerente a essa área do conhecimento desde sua origem. Contribuindo assim, conforme destacado por Morin (2002) para a "religação dos saberes", tão necessária, especialmente, no atual contexto para o entendimento da complexidade do mundo em que vivemos. 
Muitas vezes, a paisagem não consiste o objeto de estudo em si, todavia, a sua apreensão em vários campos do conhecimento torna-se necessária, visto que, a mesma pode consistir em um "instrumento" para a compreensão de determinado objeto.

A paisagem urbana é dinâmica, sua produção e transformações resultam das adaptações do meio pela sociedade, reflete as características da produção espacial, revela segregações e diferentes tempos históricos materializados, sendo, portanto, histórica e conforme coloca Duncan (2004, p.97) um componente característico dos processos sociais. Neste sentido, são inerentes à paisagem urbana, como elementos constitutivos, as transformações decorrentes da dinâmica, bem como as permanências. Essa paisagem, conforme alertado por Carlos $(1992$, p.41) é composta pela dimensão material e pela movimentação cotidiana.

A fim de compreender a paisagem urbana deve-se levar em consideração os diversos processos de reprodução social e produção do espaço, os quais são determinados pelos anseios e valores de determinado período histórico. A cultura, através das imagens e memórias, exerce grande importância nesse processo de apreensão da paisagem, sendo necessária para tanto que sejam envolvidos a percepção sensorial e o subjetivismo, inerentes à fenomenologia.

\section{Referências}

ABREU, Mauricio de Almeida. Pierre Monbeig e os primórdios da geografia urbana no Brasil. In Pierre Monbeig e a geografia humana brasileira: a dinâmica da transformação. SALGUEIRO, Heliana Angoti (org). Bauru, SP: Edusp, 2006, p.129-158.

BERTRAND, Georges; BERTRAND, Claude. Uma Geografia transversal e de travessias: o meio ambiente através dos territórios e das temporalidades. PASSOS, Messias Modesto dos (orgs). Maringá: Ed. Massoni, 2007.

BERQUE, Augustin. Paisagem-Marca, Paisagem-Matriz: Elementos da Problemática para uma Geografia Cultural. In: ROSENDHAL, Zeny; CORREA, Roberto Lobato. (orgs). Paisagem, Tempo e Cultura. Rio de Janeiro: EDUERJ, 2000.

CARLOS, Ana Fani Alessandri. A (re)produção do espaço urbano. São Paulo: Edusp, 1994. 270p.

CASTRO, Iná Elias de. Paisagem e turismo. De estética, nostalgia e política. In: YÁZIGI, Eduardo (org.). Paisagem e Turismo. São Paulo: Contexto, 2002. 226p. p.121-140 (Coleção Turismo).

CORREA, Roberto Lobato Correa. O espaço Urbano. 3 ed. São Paulo: Ática, 1995. (Série Princípios). 
O urbano e a cultura alguns estudos. In:cultura, espaço e o urbano. CORRÊA, Roberto Lobato, ROSENDAL, Zeny (org). Rio de Janeiro: EdUERJ, 2006, p.141-165.

CORRÊA, Roberto Lobato \& ROZENDAHL, Zeny. Apresentando leituras sobre paisagem, tempo e cultura. In: CORREAA, Roberto Lobato \& ROZENDAHL, Zeny (orgs.). Paisagem, Tempo e Cultura. Rio de Janeiro: Eduerj, 1998. p.7-11.

DARDEL, E. L'homme et al terre - nature de la réalite geographyque. Paris: CTHS, 1990.

FREITG-ROUANET, Barbara. Vida urbana e cultura. In:cidade e cultura: esfera publica e transformação urbana. (org) Vera M. Pallamin, coord. Marina Ludemann. - São Paulo: Estação liberdade, 2002. p. 27-36.

GOMES, Edvânia Torres Aguiar. Recortes de paisagens na cidade do Recife: uma abordagem geográfica. 1997. 300f. Tese (Doutorado)-USP. Faculdade de Filosofia, Letras e Ciencias Humanas. São Paulo, 1997.

HOLZER, Werther. Paisagem Imaginário e Identidade: alternativas para o estudo geográfico. In: ROSENDAHL, Zeny \& CORRÊA, Roberto Lobato (orgs). Manifestações da Cultura no Espaço. Rio de Janeiro: Eduerj, 1999. 248p. p.149-168 (Série Geografia Cultural).

LEMENHE, José Antônio O.P. Paisagem urbana e utopias. In: A cidade e o urbano: temas para debates. SILVA, José Borzacchiello, COSTA, Maria Clelia Lustosa, DANTAS, Eutógio Wanderley Correia Dantas (org). Fortaleza: EUFC, 1997. 163-170.

MONTESSORO, Cláudia Cristina Lopes. Shopping Centers e (re)estruturação urbana em Presidente Prudente. - SP. 1999. Dissertação (Mestrado) - UNESP. Faculdade de Ciencias e Tecnologia. Presidente Prudente, 1999.

MORAES, Antônio Carlos Robert de. Geografia: pequena historia crítica. São Paulo: Hucitec, 1991.

MORAES, Antonio Carlos Robert; COSTA, Wanderly Messias da Costa. Geografia critica: a valorização do espaço. São Paulo: HUCITEC, 1999. 196 p.

MORIN. Edgar. A religação dos saberes: o desafio do século XXI. Rio de Janeiro: Bertrand Brasil, 2002.

MOURA, Gerusa Gonçalves. Imagens e representações da periferia de Uberlândia(MG): Um estudo de caso do setor oeste. 2003. Dissertação de Mestrado - UFU. Instituto de Geografia. Uberlândia, 2003.

NOBRE, Paulo José Lisboa. Entre o cartão-postal e a cidade real:Um estudo sobre paisagem e produção imobiliária em Natal/RN. Dissertação de Mestrado - UFRN. Faculdade de Arquitetura e Urbanismo. Natal. Rio Grande do Norte.2001.

PEIXOTO, Nelson Brissac. Paisagens urbanas. São Paulo: Editora Senac, São Paulo, 2004. 
PRIGGE, Walter. Metropolização. In: cidade e cultura: esfera publica e transformação urbana. (org) Vera M. Pallamin, coord. Marina Ludemann. - São Paulo: Estação liberdade, 2002. p. 51-58.

TROLL, Carl. A Paisagem Geográfica e sua investigação. Espaço e Cultura - NEPEC. Rio de Janeiro, nº 2, p. 1-7, jun. 1996.

RELPH, Eduard C. A paisagem urbana moderna. Rio de Janeiro :Edição 70, 1987.

SALGUEIRO, Heliana Angoti. Introdução de Território, paisagem e cidade na obra de Pierre Monbeig. In: Pierre Monbeig e a geografia humana brasileira: a dinâmica da transformação. SALGUEIRO, Heliana Angoti (org). Bauru, SP: Edusp, 2006. p.89-115.

SANTOS, Milton. Técnica, Espaço, Tempo: Globalização e Meio Técnico-cientificoinformacional. São Paulo: Hucitec, 1996.

Metamorfoses do espaço habitado. São Paulo: Hucitec,1997.

SAUER, Carl. O. A morfologia da paisagem. CORRÊA, R.L.; ROSENDAHL, Z. (orgs) In: Paisagem, Tempo e Cultura. EdUERJ. $2^{\mathrm{a}}$ ed. 2004.

SCHIER, Raul Alfredo. Trajetórias do conceito de paisagem na Geografia. Curitiba, $\mathrm{n}^{\circ} 7$, p. 79-85, Ed. UFPR. 2003.

SILVEIRA, Pedro Castelo Branco. Etnografia da paisagem: natureza, cultura e hibridismo em São Luiz do Paraitinga. Campinas, São Paulo: [s. n.], Tese (doutorado em Ciências Sociais) - Universidade Estadual de Campinas, Instituto de Filosofia e Ciências Humanas. 2008. 